\title{
MONTMORILONITA MODIFICADA COMO CATALISADOR HETEROGÊNEO EM REAÇÕES DE ESTERIFICAÇÃO (M)ETÍLICA DE ÁCIDO LÁURICO
}

\author{
Leandro Zatta, Angelita Nepel, Andersson Barison e Fernando Wypych* \\ Departamento de Química, Universidade Federal do Paraná, CP 19081, 81531-980 Curitiba - PR, Brasil
}

Recebido em 31/8/11; aceito em 22/5/12; publicado na web em 24/8/12

\begin{abstract}
MODIFIED MONTMORILLONITE AS A HETEROGENEOUS CATALYST IN (M)ETHYL ESTERIFICATION REACTION OF LAURIC ACID. Montmorillonite was modified with zirconium polyoxycations in the presence of ammonium sulphate. The material was characterized and used as a catalyst in the esterification of lauric acid, the reactions being accompanied by $2^{3}$ factorial design. Conversions of up to 95.33 and $83.35 \%$ were observed for the methyl and ethyl esterification reactions respectively, proving superior to results obtained by thermal conversion. The material was submitted to three reaction cycles and similar conversions were observed, indicating the catalyst is not significantly deactivated after reuse. The catalyst was also tested under reflux conditions, yielding a maximum conversion of $36.86 \%$.
\end{abstract}

Keywords: biodiesel; esterification; montmorillonite.

\section{INTRODUÇÃO}

A depleção de recursos obtidos a partir do petróleo aplicados à produção de combustíveis e questões relacionadas a problemas ambientais são os principais objetivos na crescente investigação a respeito de fontes alternativas para obtenção de combustíveis. Neste contexto busca-se um substituto aos combustíveis de origem fóssil, que apresentem características equivalentes ou superiores, para uso em motores à combustão interna, aplicados principalmente nas áreas de transporte e indústria. ${ }^{1}$

O biodiesel surge como um combustível alternativo, considerado um possível substituto parcial ou total ao óleo diesel convencional, além de apresentar características como biodegradabilidade, baixa toxidez, proveniência de fontes renováveis e, ainda, emissão reduzida de materiais particulados, de gases como $\mathrm{CO}$ e $\mathrm{SO}_{2}$ (exceto $\mathrm{NO}_{\mathrm{x}}$ ), compostos orgânicos voláteis, além de hidrocarbonetos. ${ }^{2,3} \mathrm{O}$ biodiesel possui propriedades físico-químicas similares ao diesel, podendo ser utilizado na forma pura diretamente em motores à diesel ou misturado ao óleo diesel. ${ }^{2,4}$ A produção de biodiesel ocorre majoritariamente através de dois processos, a transesterificação de óleos vegetais e gorduras animais refinados e a esterificação de ácidos graxos livres, obtidas a partir da hidrólise de gorduras animais e óleos vegetais brutos. ${ }^{5-7}$

A esterificação de ácidos graxos vem despertando um grande interesse mundial devido à possibilidade de se utilizar matérias-primas com baixo valor agregado na produção de combustíveis, como borras contendo grandes quantidades de ácidos graxos livres. Este processo consiste na reação de um ácido carboxílico com um álcool na presença de um catalisador ácido, conduzindo à formação de éster e água, como subproduto. ${ }^{8,9}$ As reações de esterificação de ácidos graxos livres podem ser catalisadas por ácidos de Brönsted, tanto no meio homogêneo quanto heterogêneo. ${ }^{9}$ É conhecida a utilização de ácidos minerais em meio homogêneo, como o sulfúrico, p-tolueno sulfônico, clorídrico, entre outros..$^{10,11} \mathrm{O}$ uso destes catalisadores também causa inconvenientes como a corrosão de equipamentos, o consumo do catalisador, além de utilização de grandes volumes de águas na lavagem dos produtos, consequentemente gerando problemas ambientais. ${ }^{10}$

*e-mail: wypych@ufpr.br
Existem muitos estudos envolvendo catalisadores heterogêneos contendo sítios ácidos de Brönsted e Lewis, ${ }^{12}$ onde é conhecida a aplicação de materiais como resinas de troca iônica, zeólitas, heteropoliácidos suportados em diferentes materiais, óxidos metálicos, entre outros. ${ }^{10} \mathrm{~A}$ vantagem dos catalisadores heterogêneos consiste na fácil separação do produto, reciclagem/reuso do catalisador, redução da corrosão de equipamentos e capacidade de processar reações de esterificação e transesterificação, muitas vezes de forma simultânea. Esta classe de catalisadores ainda pode ser fixada em uma coluna em reatores de fluxo contínuo, facilitando a separação e purificação dos produtos. ${ }^{13}$ Como desvantagens em relação à catálise homogênea, os sistemas heterogêneos apresentam menores rendimentos, maiores tempos devem ser utilizados e exigem maiores temperaturas de reação.

De modo geral, a maioria dos catalisadores heterogêneos empregados em reações de (trans)esterificação possuem limitações em sua aplicação industrial, devido a altos custos ou complexidade das operações envolvidas no seu preparo. ${ }^{14}$ Neste contexto, busca-se a aplicação de catalisadores que além de apresentarem uma boa atividade catalítica, possuam baixo valor agregado. Recentemente, a haloisita e outros argilominerais in natura foram investigados na esterificação (m)etílica do ácido láurico, apresentando boas conversões a ésteres metílicos, possibilidade de reuso, aliados ao baixo custo. ${ }^{15}$

Os argilominerais têm recebido atenção considerável no contexto de produção de biodiesel por serem ambientalmente compatíveis, amplamente disponíveis a um baixo custo, de fácil recuperação do meio reacional, possuírem alta seletividade e estabilidade térmica, apresentarem possibilidade de reuso, além de reduzirem a maioria dos problemas apresentados pela catálise em meio homogêneo. ${ }^{8,10,16}$ Estes materiais agregam propriedades como a alta seletividade e são aplicadas condições brandas de reação. ${ }^{17}$

As espécies químicas mais comumente utilizadas na modificação de argilominerais (normalmente por troca iônica e/ou pilarização) são os polioxicátions de alumínio, ferro, cério, cromo, gálio, lantânio, silício, titânio e zircônio, ${ }^{18,19}$ além da possibilidade de se utilizar misturas destes. ${ }^{4,20}$ Os argilominerais mais comumente utilizados pertencem à classe dos filosilicatos trocadores catiônicos do grupo 2:1, dos quais os mais comuns são a montmorilonita, a nontronita e a saponita.

O objetivo deste trabalho foi modificar quimicamente o argilomineral montmorilonita através da interação com polioxicátions de 
zircônio na presença de sulfato de amônio, caracterizar o material obtido e investigar sua atividade catalítica na reação de esterificação metílica e etílica do ácido láurico. Para evitar a influência de vários contaminantes existentes nos argilominerais comerciais, optou-se por utilizar um material padrão internacional, porém o procedimento pode ser facilmente adaptado a amostras comerciais. Pelo baixo custo dos argilominerais e a facilidade da modificação química proposta por este trabalho visa-se o emprego do catalisador preparado na esterificação de ácidos graxos derivados de óleos vegetais e gorduras animais brutas.

\section{PARTE EXPERIMENTAL}

\section{Materiais}

O argilomineral montmorilonita (MMT) utilizado (STx-1), de fórmula química $(\mathrm{Na}, \mathrm{Ca})_{0.33}(\mathrm{Al}, \mathrm{Mg})_{2} \mathrm{Si}_{4} \mathrm{O}_{10}(\mathrm{OH})_{2} \cdot \mathrm{nH}_{2} \mathrm{O},{ }^{21}$ é proveniente de Gonzales County, Estados Unidos e fornecida como um padrão pela Clay Minerals Society. Apesar de ser um padrão internacional, o argilomineral é contaminado com teores relativamente altos de minerais inertes como a opala, um mineral de sílica (cristobalita e tridimita) e quartzo ( $30 \%$ de opala e $3 \%$ de quartzo).

Os reagentes utilizados foram $\mathrm{NaCl}$ (Vetec - 99\%), $\mathrm{AgNO}_{3}$ (Merck - 99,99\%), $\mathrm{ZrOCl}_{2}$ (Sigma-Aldrich - 99,5\%), $\left(\mathrm{NH}_{4}\right)_{2} \mathrm{SO}_{4}$ (Vetec-99\%), $\mathrm{Na}_{2} \mathrm{CO}_{3}$ (Reagen - 99,9\%), $\mathrm{NaOH}$ (Vetec - 98\%). As reações de esterificação foram realizadas com reagentes comerciais, os quais foram utilizados como recebidos: ácido láurico $\left(\mathrm{C}_{12} \mathrm{H}_{24} \mathrm{O}_{2}\right.$, Vetec - 98\%), metanol (QEEL - 99,8\%) e etanol (Synth - 99,8\%).

\section{Métodos}

\section{Preparação do catalisador}

$\mathrm{O}$ argilomineral original (MMT) foi inicialmente saturado com íons sódio (Na-MMT), através da suspensão do material em água ( $1 \%$ ) com a subsequente adição de $\mathrm{NaCl}$, de forma que a quantidade adicionada deste sal foi de cinco vezes a capacidade de troca catiônica da montmorilonita, que é de $89 \mathrm{meq} 100 \mathrm{~g}^{-1}{ }^{22} \mathrm{O}$ material resultante foi lavado até teste negativo para a presença de íons cloreto, através do teste com $\mathrm{AgNO}_{3}$.

Para a síntese do catalisador, foi preparada uma solução a partir da dissolução de $\mathrm{ZrOCl}_{2} \cdot 8 \mathrm{H}_{2} \mathrm{O}$ e $\left(\mathrm{NH}_{4}\right)_{2} \mathrm{SO}_{4}$ de maneira que a razão $\mathrm{SO}_{4}{ }^{2-} / \mathrm{Zr}^{4+}$ fosse igual a 0,14 ; em seguida, o $\mathrm{pH}$ da solução resultante foi ajustado para 2,8 com a adição de solução $1 \mathrm{~mol} \mathrm{~L}^{-1}$ de $\mathrm{Na}_{2} \mathrm{CO}_{3}$. $\mathrm{A}$ amostra Na-MMT foi adicionada à solução anteriormente descrita mantendo a razão $\mathrm{Zr} / \mathrm{Na}-\mathrm{MMT}=7,6 \times 10^{-3} \mathrm{~mol} \mathrm{~g}^{-1}$. A suspensão resultante foi sonicada durante $20 \mathrm{~min}$ e o material obtido foi lavado até teste negativo para íons cloreto, seco por $12 \mathrm{~h}$ a $100{ }^{\circ} \mathrm{C}$ e calcinado a $450{ }^{\circ} \mathrm{C}$ por $4 \mathrm{~h}$.

\section{Reações de esterificação}

As reações de esterificação foram conduzidas em um reator Cyclone Büchiglasuster, modelo miniclave drive. A pressão interna do vaso de reação correspondeu à pressão de vapor do componente mais volátil da mistura, ou seja, o álcool utilizado. O catalisador empregado foi separado do meio reacional após as reações por centrifugação e o excesso de álcool foi recuperado por rotaevaporação, o material sólido foi lavado com $15 \mathrm{~mL}$ da mistura etanol/hexano na proporção $1: 1$, centrifugado e seco em estufa a $90{ }^{\circ} \mathrm{C}$ durante 12 h. Foram empregadas também como condições padrões em todas as reações, tempos de $2 \mathrm{~h}$ e agitação de $500 \mathrm{rpm}$, valores obtidos em experimentos prévios.

As reações de esterificação metílica do ácido láurico também foram realizadas sob condições de refluxo, à temperatura de ebulição do metanol $\left(63^{\circ} \mathrm{C}\right)$, utilizando-se um balão de fundo redondo e tempo reacional de $2 \mathrm{~h}$. As conversões a ésteres (m)etílicos foram quantificadas pela determinação do número de ácidos livres, de acordo com o método AOCS - Ca-5a-40 da American Oil Chemist's Society, ${ }^{23}$ para o qual foi verificada uma boa correlação com o método de cromatografia líquida de alta eficiência em trabalhos realizados no grupo de pesquisa, onde se determinaram as conversões de laurato de metila. ${ }^{24}$

Com a finalidade de aumentar a confiabilidade dos resultados obtidos pelo método AOCS, a conversão a ésteres (m)etílicos também foi determinada através da espectroscopia de ressonância magnética nuclear $(\mathrm{RMN})$ de ${ }^{1} \mathrm{H}$. Neste procedimento, foram transferidas alíquotas de aproximadamente $100 \mu \mathrm{L}$ dos produtos das reações diretamente para tubos de RMN de $5 \mathrm{~mm}$ e o volume completado com cerca de $500 \mu \mathrm{L}$ de $\mathrm{CDCl}_{3}$ contendo $1 \%$ de TMS. Os espectros de RMN de ${ }^{1} \mathrm{H}$ foram adquiridos à temperatura ambiente (aproximadamente $22^{\circ} \mathrm{C}$ ) em um espectrômetro de RMN Bruker Avance 400 operando a 9,4 Tesla, observando o núcleo de hidrogênio a 400,13 MHz, equipado com uma sonda multinuclear de observação direta de $5 \mathrm{~mm}$ e gradiente em z. Os espectros de $\mathrm{RMN}$ de ${ }^{1} \mathrm{H}$ foram adquiridos com $64 \mathrm{~K}$ pontos através de pulsos de excitação de $90^{\circ}$, acúmulo de 16 varreduras, janela espectral de $\sim 9,5$ ppm e tempo de relaxação de 2,5 s. Os espectros de RMN de ${ }^{1} \mathrm{H}$ foram processados com auxílio do programa TOPSPIN, aplicando-se inicialmente uma multiplicação exponencial dos FIDs por um fator de $0,3 \mathrm{~Hz}$, seguido da transformada de Fourier para construção dos espectros com $128 \mathrm{~K}$ pontos. Os deslocamentos químicos foram expressos em ppm $(\delta)$ em relação ao sinal do TMS em 0,00 ppm, utilizado como referência interna.

\section{Caracterizações}

As medidas de difração de raios X pelo método pó (XRD) foram obtidas depositando-se os materiais em porta-amostras de vidro neutro, utilizando-se um difratômetro Shimadzu modelo XRD-6000. Utilizou-se uma fonte de radiação de cobre $\mathrm{CuK}=1,5418 \AA$, corrente de $30 \mathrm{~mA}$ e tensão de $40 \mathrm{KV}$ e as medidas foram adquiridas a uma velocidade de varredura de $2^{\circ} \mathrm{min}^{-1}$ e passo de 0,02 graus.

Os espectros vibracionais na região do infravermelho (FTIR) foram obtidos pelo modo transmissão em um equipamento BioRad, Modelo FTS 3500GX, mediante o uso de pastilhas de $\mathrm{KBr}$, com acumulação de 32 transientes na faixa dos 400 aos $4000 \mathrm{~cm}^{-1} \mathrm{e}$ resolução de $4 \mathrm{~cm}^{-1}$.

A identificação de sítios ácidos foi realizada através da calcinação prévia de cerca de $100 \mathrm{mg}$ de amostra a $400{ }^{\circ} \mathrm{C}$ durante $90 \mathrm{~min}$, a qual foi esfriada $120^{\circ} \mathrm{C}$. A amostra foi saturada com piridina gasosa diluída em $\mathrm{N}_{2}$ durante $60 \mathrm{~min}$. Após o processo de sorção da piridina, a amostra foi mantida a $120^{\circ} \mathrm{C}$ e sob fluxo de $\mathrm{N}_{2}$ durante $60 \mathrm{~min}$, com o objetivo de remover a piridina fisicamente adsorvida. O espectro de FTIR foi coletado na faixa de $1650-1350 \mathrm{~cm}^{-1}$, com resolução de 4 $\mathrm{cm}^{-1}$. Os sítios ácidos foram identificados pela análise do espectro de FTIR da piridina, a qual gera espécies com frequências de vibração características que são correlacionadas aos respectivos sítios ácidos de Lewis e Brönsted..$^{25}$

As medidas simultâneas de TGA/DTA foram realizadas utilizando-se um equipamento Mettler Toledo TG/s-DTA 851 E. As amostras foram alocadas em cadinhos de platina e submetidas a um programa de aquecimento de $10^{\circ} \mathrm{C} \mathrm{min}{ }^{-1}$, sob fluxo de oxigênio de $50 \mathrm{~mL} \mathrm{~min}^{-1}$.

Foram obtidas medidas de microscopia eletrônica de varredura (SEM) utilizando-se um microscópio JEOL (JSM-6360LV), com uma tensão de $15 \mathrm{kV}$. As amostras foram depositadas em um porta-amostras com fita adesiva de cobre e cobertas com uma fina camada de ouro. Além das imagens, as composições químicas foram obtidas pela técnica de espectroscopia por dispersão em energia (EDS), utilizando-se um equipamento Thermo Noran e um software Noran System Six. 
As isotermas de adsorção de nitrogênio foram obtidas em um analisador de sorção de gás Quantachrome, modelo NOVA 2000e. As amostras foram degaseificadas à $300^{\circ} \mathrm{C}$ sob vácuo durante $3 \mathrm{~h}$ e as análises foram conduzidas sob temperatura de nitrogênio líquido $\left(-196^{\circ} \mathrm{C}\right)$. As áreas superficiais específicas das amostras foram calculadas utilizando o método com pontos-múltiplos Brunauer-EmmetTeller (BET) e as análises de volume e tamanho médio de poros foram obtidas utilizando o modelo BJH, pela análise da curva de adsorção.

\section{RESULTADOS E DISCUSSÃO}

\section{Caracterização do catalisador}

Através da técnica de XRD (Figura 1) analisou-se o padrão de difração de raios $\mathrm{X}$ da montmorilonita STx-1 sem tratamento prévio (MMT), após suspensão em solução de cloreto de sódio (Na-MMT) e após suspensão da amostra Na-MMT na solução de zircônio e íons sulfato e subsequente calcinação (Na-MMT- $\mathrm{ZrSO}_{4}$ ). Os picos da montmorilonita foram indexados (Figura 1a) e o espaçamento basal foi de $15,43 \AA$, valor determinado pela equação de Bragg a partir do pico de maior ordem (005). ${ }^{26} \mathrm{~A}$ escolha desse pico baseia-se no fato de que quando maior o valor do ângulo, maior a precisão da medida da distância interplanar.

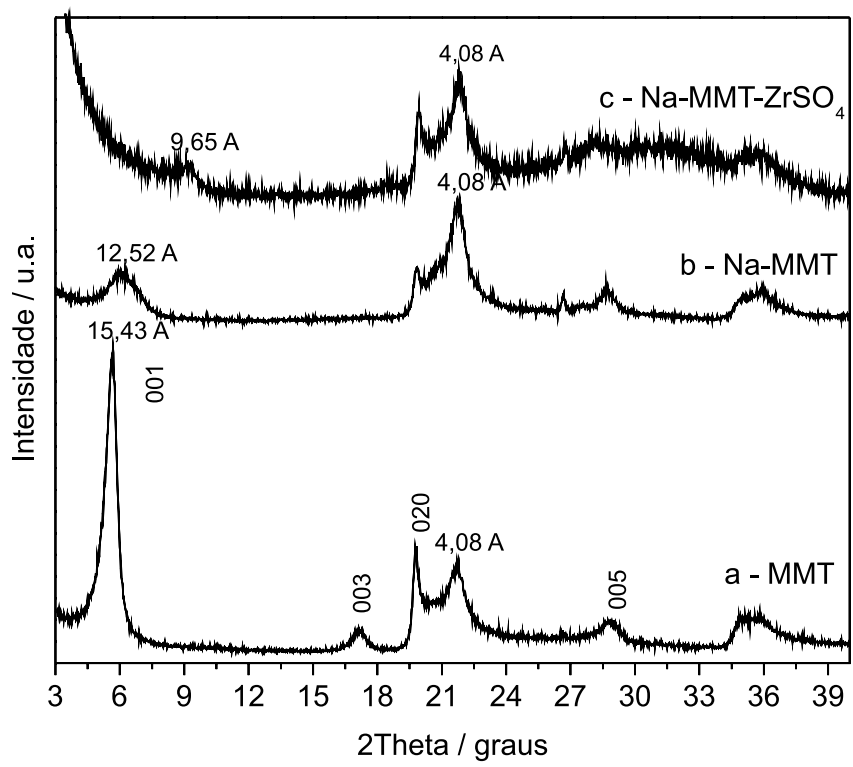

Figura 1. Difratogramas de raios $X$ da amostra MMT (a), Na-MMT (b) e $\mathrm{Na}-\mathrm{MMT}_{-} \mathrm{ZrSO}_{4}(\mathrm{c})$

Devido ao tratamento com solução de $\mathrm{NaCl}$, a montmorilonita (Na-MMT) (Figura 1b) passou a apresentar espaçamento basal de $12,52 \AA$ e esta amostra foi utilizada como precursor na modificação com zircônio e sulfato. A amostra modificada com estes íons apresenta como diferença principal em relação às amostras precursoras, a presença de um pico de baixa intensidade em 9,65 A na amostra Na-MMT-ZrSO ${ }_{4}$ (Figura 1c), para tal supõe-se que a presença de íons zircônio e sulfato na solução contribuiu para a formação de uma nova fase. Para todas as amostras avaliadas, observa-se um pico em $4,08 \AA$, o qual pode ser atribuído à contaminação de opala (cristobalita/tridimita). ${ }^{21}$ Apesar do alto teor de zircônio (Tabela 1), não são observados picos relativos a nenhuma fase cristalina contendo esse elemento, demonstrando que está incorporado à amostra em uma fase amorfa e provavelmente de uma forma homogênea, como comprovado pelo mapeamento da distribuição do zircônio na amostra, pela técnica de EDS (dados não mostrados).
Tabela 1. Razões atômicas entre os principais elementos constituintes das amostras antes e após o processo de incorporação do zircônio (medidas de EDS)

\begin{tabular}{lcccc}
\hline Amostra & $\mathrm{Si} / \mathrm{Al}$ & $\mathrm{Si} / \mathrm{Zr}$ & $\mathrm{Al} / \mathrm{Zr}$ & $\mathrm{Zr} / \mathrm{S}$ \\
\hline $\mathrm{Na}-\mathrm{MMT}$ & 9,93 & - & - & - \\
$\mathrm{Na}^{-M M T}-\mathrm{ZrSO}_{4}$ & 10,55 & 1,92 & 5,50 & 4,56 \\
\hline
\end{tabular}

As composições químicas das amostras Na-MMT e Na-MMT$\mathrm{ZrSO}_{4}$ foram determinadas pela técnica de EDS, cujos resultados são apresentados pela Tabela 1 .

No material suplementar são mostrados os espectros de FTIR

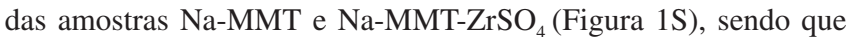
para efeito de comparação, a primeira foi calcinada sob as mesmas condições que a amostra modificada com zircônio. Para a amostra Na-MMT- $\mathrm{ZrSO}_{4}$ verifica-se a presença dos elementos zircônio e enxofre (Tabela 1), a identificação desta última corrobora o alargamento da banda entre 850 a $1500 \mathrm{~cm}^{-1}$ no espectro de FTIR desta amostra (Figura 1S) demonstrando a presença de íons sulfato no material. A amostra de montmorilonita após troca pelo sódio apresenta uma razão atômica $\mathrm{Si} / \mathrm{Al}$ de 9,93 , enquanto que a amostra modificada apresenta esta razão atômica de 10,55, indicando que houve lixiviação de alumínio (além do magnésio) possivelmente devido ao baixo $\mathrm{pH}$ empregado durante o processo de incorporação do zircônio.

O processo de lixívia é corroborado pela comparação dos espectros de FTIR (Figura 1Sb) destes materiais, em que se verifica a diminuição das bandas referentes às vibrações $\mathrm{Al}-\mathrm{OH}, \mathrm{Al}-\mathrm{O}$ e Si-Al-O em 915,626 e $524 \mathrm{~cm}^{-1}$, respectivamente, além da banda em $840 \mathrm{~cm}^{-1}$, relativa à vibração do grupamento $\mathrm{O}-\mathrm{H}$ ligado ao íon magnésio. ${ }^{27,28}$ Verifica-se ainda a ausência de cálcio na amostra Na-MMT (dados não mostrados), demonstrando que o processo de troca catiônica pelo íon sódio foi eficiente. Observa-se nos espectros do precursor Na-MMT (Figura 1Sa) e da amostra tratada (Na-MMT-ZrSO ${ }_{4}$ ) (Figura 1Sb) que a principal diferença se situa na região de vibrações de grupamentos hidroxila (3800-2800 $\left.\mathrm{cm}^{-1}\right)$, onde na amostra modificada observa-se um pico bem definido e intenso em $3647 \mathrm{~cm}^{-1}$ e uma banda larga em $3240 \mathrm{~cm}^{-1}$. A presença destas bandas se deve possivelmente à presença de polioxicátions de zircônio interagindo com a estrutura lixiviada da montmorilonita. São verificadas também vibrações características do precursor na amostra modificada (Figura 1Sb) em 1089, 793 e 476 $\mathrm{cm}^{-1}$, devidas às vibrações das ligações $\mathrm{Si}-\mathrm{O}-\mathrm{Si}$ e $\mathrm{Si}$-O. Uma segunda diferença apresentada pela amostra Na-MMT-Z $\mathrm{rSO}_{4}$ consiste em um alargamento da banda compreendendo $850-1500 \mathrm{~cm}^{-1}$, isso se deve possivelmente à sobreposição de vibrações $\mathrm{Si}-\mathrm{O}$ com vibrações do íon sulfato em torno de $1364 \mathrm{~cm}^{-1} .^{29}$

As micrografias das amostras MMT, Na-MMT e Na-MMT-ZrSO, obtidas por microscopia eletrônica de varredura, são mostradas no material suplementar (Figura 2S). Para a amostra MMT (Figura 2Sa,b) verifica-se que as partículas apresentam uma dispersão irregular de tamanhos e de morfologias. Este argilomineral após tratamento com solução de cloreto de sódio (Figura 2Sc,d) apresenta cristais com tamanhos menores em relação ao precursor MMT e distribuição de forma mais regular. Já para a amostra tratada com a solução de zircônio e sulfato (Figura 2Se,f), verifica-se uma maior aglomeração das partículas e maior irregularidade na dispersão de tamanhos. Esse efeito se deve à desagregação dos cristais, devido ao efeito de interação da montmorilonita com as espécies de zircônio e sulfato e agitação magnética.

Pelo perfil de decomposição térmica do catalisador Na-MMT$\mathrm{ZrSO}_{4}$ (Figura 3S), observa-se que entre a temperatura ambiente e cerca de $150{ }^{\circ} \mathrm{C}$ (pico endotérmico centrado em $60^{\circ} \mathrm{C}$ ) ocorre o processo de desidratação da amostra. O material é estável até cerca 
de $500{ }^{\circ} \mathrm{C}$ (pico endotérmico largo centrado em $630{ }^{\circ} \mathrm{C}$ ), onde ocorre a desidroxilação e decomposição gradativa do material, obtendo-se os respectivos óxidos. O processo de desidroxilação demonstra que grande parte da estrutura da montmorilonita é preservada após a incorporação do zircônio e íons sulfato, o que seria esperado quando da lixívia de somente um baixo teor de íons alumínio da sua estrutura.

Os valores de área superficial específica e de volume de poro das amostras são mostrados na Tabela 2.

Tabela 2. Propriedades texturais das amostras avaliadas

\begin{tabular}{lccc}
\hline Amostra & $\begin{array}{c}\text { Área específica } \\
\left(\mathrm{m}^{2} \mathrm{~g}^{-1}\right)\end{array}$ & $\begin{array}{c}\text { Volume de poro } \\
\left(\mathrm{cm}^{\mathrm{b}} \mathrm{g}^{-1}\right)\end{array}$ & $\begin{array}{c}\text { Raio médio de } \\
\text { poro }^{\mathrm{b}}(\AA)\end{array}$ \\
\hline MMT & 50,03 & 0,117 & 15,36 \\
Na-MMT & 77,95 & 0,154 & 22,09 \\
Na-MMT-ZrSO & 166,80 & 0,128 & 17,29 \\
\hline
\end{tabular}

a Área superficial específica determinada pelo método pontos múltiplos - BET.

${ }^{\mathrm{b}}$ Volume e tamanho médio de poros foram determinados pelas curvas de adsorção utilizando o modelo BJH.

Verifica-se que a suspensão da montmorilonita em solução de cloreto de sódio causa um aumento na área superficial específica, passando de 50,03 para 77,95 m² $\mathrm{g}^{-1}$. Para a amostra Na-MMT-ZrSO o valor encontra-se em $166,80 \mathrm{~m}^{2} \mathrm{~g}^{-1}$; as possíveis explicações para isso se devem à lixiviação do alumínio e magnésio da estrutura da montmorilonita, aumentando a razão atômica de Si/Al (Tabela 1), amorfização parcial do material, como verificado por difração de raios X (Figura 1c) e a diminuição do tamanho dos aglomerados de cristais em comparação ao precursor Na-MMT, como observado pelas micrografias eletrônicas (Figura 2S, material suplementar).

As isotermas de adsorção/dessorção dos materiais são mostradas na Figura 2.

Comparando as curvas das amostras, constata-se que a amostra Na-MMT-ZrSO $\mathrm{S}_{4}$ adsorve/dessorve um maior volume de $\mathrm{N}_{2}$, isso se deve à maior área superficial apresentada por este material, como mostrado na Tabela 2.

Verifica-se que as isotermas de adsorção/dessorção de $\mathrm{N}_{2}$ da amostra Na-MMT-ZrSO ${ }_{4}$ (Figura 2c) são do tipo IV, de acordo com a classificação da IUPAC, onde a abertura da curva na pressão relativa próxima a 0,4 indica a presença de pequenos mesoporos no adsorbato. A histerese verificada é do tipo H3, caracterizando partículas em forma de placas dando origem a poros em formas de fendas, ${ }^{30}$ tal observação está de acordo com as micrografias (Figura 2Sf, material suplementar), onde são observadas partículas com morfologia tabular. A montmorilonita original (MMT) apresenta um raio médio de poro de $15,36 \AA$, enquanto que as amostras Na-MMT e Na-MMT-ZrSO apresentam valores de 22,09 e 17,29 $\AA$, respectivamente, indicando mesoporosidade nos materiais. ${ }^{30} \mathrm{O}$ fato de que a amostra MMT apresenta maior raio dos poros se deve possivelmente à sua estrutura

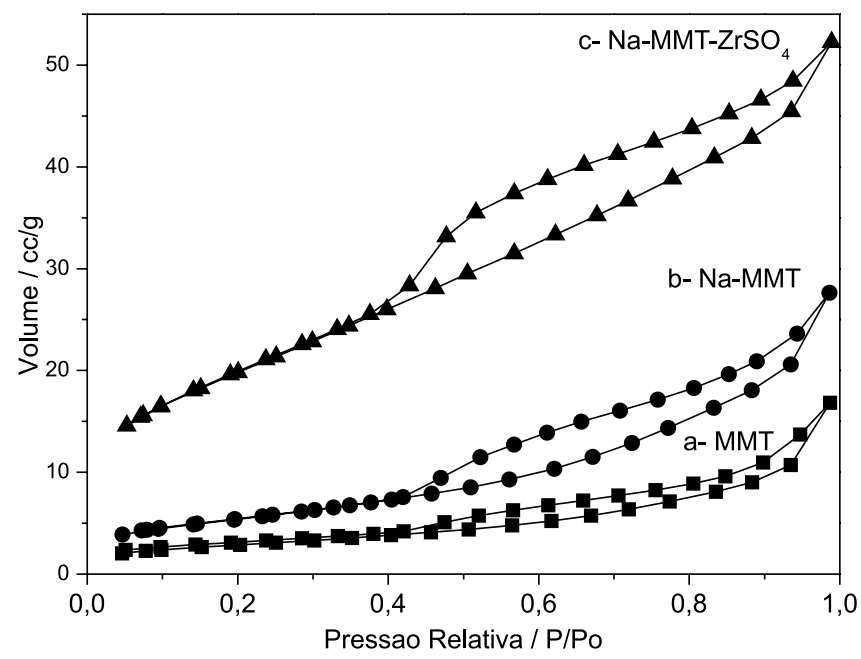

Figura 2. Isotermas de adsorção/dessorção de $N_{2}$ das amostras $\operatorname{MMT}(a)$, $\mathrm{Na}-\mathrm{MMT}$ (b) e Na-MMT-ZrSO $\mathrm{S}_{4}(\mathrm{c})$

lamelar organizada e ao maior espaçamento basal apresentado por esta, como verificado pela técnica de difração de raios X (Figura 1). Para as amostras modificadas, a diminuição do raio dos poros na amostra Na-MMT-ZrSO ${ }_{4}$ em relação ao precursor Na-MMT se deve possivelmente à interação da MMT com os polioxicátions de zircônio e íons sulfato, tanto no espaço interlamelar quanto na superfície dos cristais.

No espectro de FTIR do material Na-MMT- $\mathrm{ZrSO}_{4}$ tratado com piridina (Figura $4 \mathrm{~S}$, material suplementar) não foram observadas bandas relativas à piridina fisissorvida em $1577 \mathrm{e} 1440 \mathrm{~cm}^{-1}$. As vibrações em 1458 e $1490 \mathrm{~cm}^{-1}$ indicam a presença de sítios ácidos de Lewis, os quais possivelmente se devem à presença de cátions de zircônio e lixívia parcial do Al da estrutura da montmorilonita, como verificado pela técnica de EDS (Tabela 1). Também foi observada a vibração em $1540 \mathrm{~cm}^{-1}$ referente a sítios ácidos de Brönsted, atribuídos às hidroxilas do polioxicátion de zircônio, à hidroxilação da superfície, aos poros da montmorilonita devido ao $\mathrm{pH}$ fortemente ácido empregado na síntese do material e aos prótons trocáveis. ${ }^{31}$ A Figura 3 mostra uma representação esquemática do possível processo de lixívia e geração dos sítios de Lewis e Brönsted no material Na-MMT-ZrSO 4 .

\section{Aplicação do catalisador em reações de esterificação metílica do ácido láurico}

Inicialmente foi realizado um teste prévio para verificar a atividade catalítica do catalisador Na-MMT- $\mathrm{ZrSO}_{4}$ e de um material preparado em condições idênticas, porém sem a presença de sulfato de amônio (Na-MMT-Zr), em reações de esterificação metílica do

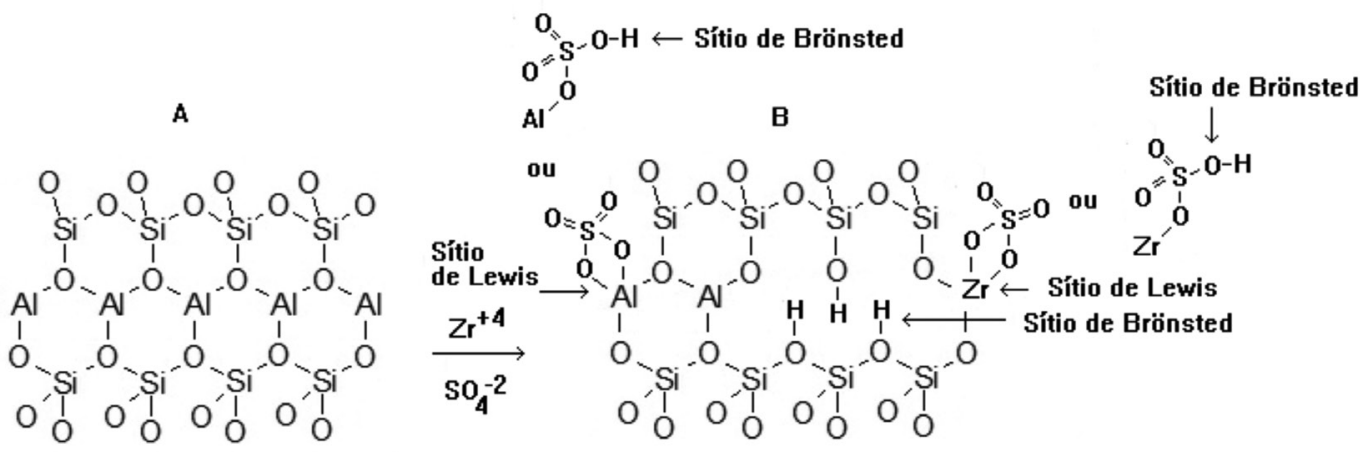

Figura 3. Possíveis fontes de sítios de Lewis e Brönsted no tratamento da amostra MMT(A) e geração do catalisador Na-MMT-ZrSO ${ }_{4}(B)$ 
Tabela 3. Planejamento fatorial $2^{3}$ para reações de esterificação metílica do ácido láurico utilizando o catalisador Na-MMT-ZrSO

\begin{tabular}{|c|c|c|c|c|c|c|c|}
\hline \multirow{2}{*}{ Ensaio } & \multicolumn{3}{|c|}{ Condições experimentais } & \multicolumn{2}{|c|}{ Resultados (titulação) } & \multirow{2}{*}{$\begin{array}{l}\text { Ganho de conversão } \\
\text { Pontos percentuais }\end{array}$} & \multirow{2}{*}{$\begin{array}{c}\text { Resultados }(\mathrm{RMN})^{* *} \\
\text { Éster }(\%)\end{array}$} \\
\hline & $\mathrm{T}\left({ }^{\circ} \mathrm{C}\right)$ & $\mathrm{RM}$ & CAT & Acidez $(\%) * *$ & Conversão (\%) & & \\
\hline 1 & 140 & $6: 1$ & $*$ & $31,10 \pm 0,98$ & 68,90 & - & $68,42 \pm 1,30$ \\
\hline 2 & 160 & $6: 1$ & $*$ & $20,77 \pm 1,00$ & 79,23 & - & $81,42 \pm 0,43$ \\
\hline 3 & 150 & $9: 1$ & $*$ & $31,56 \pm 0,93$ & 68,44 & - & $68,88 \pm 0,67$ \\
\hline 4 & 140 & $12: 1$ & $*$ & $29,75 \pm 0,25$ & 70,25 & - & $70,28 \pm 0,79$ \\
\hline 5 & 160 & $12: 1$ & $*$ & $30,21 \pm 0,36$ & 69,79 & - & $70,23 \pm 0,50$ \\
\hline 6 & $140(-)$ & $6: 1(-)$ & $8(-)$ & $9,47 \pm 0,31$ & 90,53 & 21,63 & $89,72 \pm 1,36$ \\
\hline 7 & $160(+)$ & $6: 1(-)$ & $8(-)$ & $7,14 \pm 0,21$ & 92,88 & 13,65 & $92,35 \pm 0,15$ \\
\hline 8 & $140(-)$ & $12: 1(+)$ & $8(-)$ & $12,19 \pm 0,36$ & 87,81 & 17,56 & $88,29 \pm 0,87$ \\
\hline 9 & $160(+)$ & $12: 1(+)$ & $8(-)$ & $5,27 \pm 0,19$ & 94,73 & 24,94 & $94,85 \pm 0,44$ \\
\hline 10 & $140(-)$ & $6: 1(-)$ & $12(+)$ & $6,83 \pm 0,40$ & 93,17 & 24,27 & $92,20 \pm 0,72$ \\
\hline 11 & $160(+)$ & $6: 1(-)$ & $12(+)$ & $9,21 \pm 0,66$ & 90,79 & 11,56 & $89,28 \pm 0,97$ \\
\hline 12 & $140(-)$ & $12: 1(+)$ & $12(+)$ & $9,17 \pm 0,26$ & 90,83 & 20,58 & $91,15 \pm 0,89$ \\
\hline 13 & $160(+)$ & $12: 1(+)$ & $12(+)$ & $4,67 \pm 0,37$ & 95,33 & 25,54 & $94,53 \pm 1,29$ \\
\hline 14 & $150(0)$ & 9:1 (0) & $10(0)$ & $7,87 \pm 0,49$ & 92,13 & 23,69 & $92,59 \pm 1,45$ \\
\hline 15 & $150(0)$ & $9: 1(0)$ & $10(0)$ & $8,25 \pm 0,10$ & 91,75 & 23,31 & $91,49 \pm 1,25$ \\
\hline 16 & $150(0)$ & 9:1 (0) & $10(0)$ & $6,88 \pm 0,35$ & 93,12 & 24,68 & $91,93 \pm 0,94$ \\
\hline
\end{tabular}

$\mathrm{T}$ = temperatura; $\mathrm{RM}$ = razão molar álcool:ácido láurico: $\mathrm{CAT}=$ teor de catalisador em massa em relação ao ácido láurico; os símbolos,$+-\mathrm{e} 0$ representam o maior, menor e ponto central do planejamento fatorial; $*=$ ausência de catalisador; $* *=$ medidas realizados em triplicata.

ácido láurico. Para o teste foram empregadas condições de temperatura de $160{ }^{\circ} \mathrm{C}$, razão molar 6:1 (metanol:ácido láurico), $8 \%$ de catalisador e tempo de reação de $2 \mathrm{~h}$. Quando da utilização do catalisador Na-MMT-Zr, a conversão a laurato de metila foi de $91,00 \%$ e com o catalisador Na-MMT-ZrSO $\mathrm{H}_{4}$, a conversão foi de $94,73 \%$, estes valores quando comparados ao branco de reação (reação na ausência de catalisador) mostram ganhos de conversão de 11,77 e $15,5 \%$, respectivamente. Pelo fato da amostra Na-MMT-ZrSO ${ }_{4}$ ter apresentado maior conversão no teste prévio, foi realizado um estudo mais detalhado através de planejamento fatorial $2^{3}$, considerando-se o efeito da temperatura, teor de catalisador e razão molar. O tempo de reação foi de $2 \mathrm{~h}$ em todas as reações (Tabela 3 ).

As conversões do ácido láurico a laurato de metila foram analisadas pelas técnicas de titulação de acordo com o método AOCS - Ca$5 \mathrm{a}-40,{ }^{23}$ determinando-se a acidez do produto através da titulação do ácido não reagido, bem como através da comparação das áreas dos sinais característicos nos espectros de RMN de ${ }^{1} \mathrm{H}$.

O método por RMN é baseado na relação de áreas de dois sinais característicos nos espectros de RMN de ${ }^{1} \mathrm{H}$, sendo um referente a hidrogênios presentes tanto no ácido graxo, quanto no seu respectivo éster e outro presente somente no éster. Desta forma, as eficiências de conversões a ésteres metílicos foram determinadas através da comparação das áreas dos sinais em 0,88 ppm, referente aos grupos metila terminal, presentes tanto no ácido graxo quanto no éster correspondente, ${ }^{32}$ e 3,66 ppm referente ao grupo metoxila, ${ }^{32,33}$ presente somente no éster metílico (Figura 4).

Uma vez que a relação intramolecular de hidrogênios $\left(-\mathrm{CH}_{3}\right.$ versus $-\mathrm{OCH}_{3}$ ) é de $3: 3$, ao referenciar a área do sinal em 0,88 ppm para 100, o valor encontrado para a área do sinal em 3,66 ppm irá refletir diretamente a percentagem de éster convertido. A Figura 5 mostra que o método baseado em RMN de ${ }^{1} \mathrm{H}$ apresentou boa correlação com o método de titulação, demonstrando que o mesmo também pode ser aplicado para esta finalidade (Tabela 3 ).

Os resultados para os efeitos das variáveis estudadas são discutidos a partir dos teores de éster determinados por titulação. A maior conversão a laurato de metila foi obtida na reação 13 , em que foram empregadas condições de razão molar de $12: 1$, temperatura de $160^{\circ} \mathrm{C}$

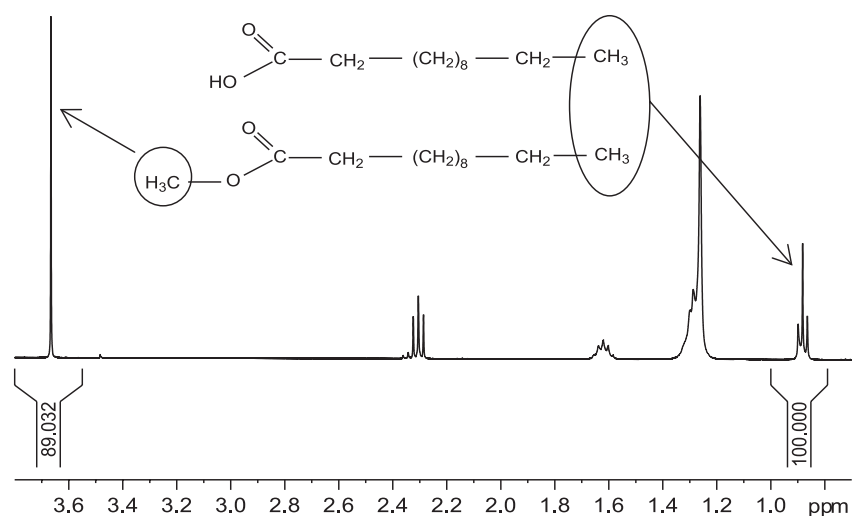

Figura 4. Determinação da percentagem de conversão a laurato de metila através de $R M N$ de ${ }^{l} H$

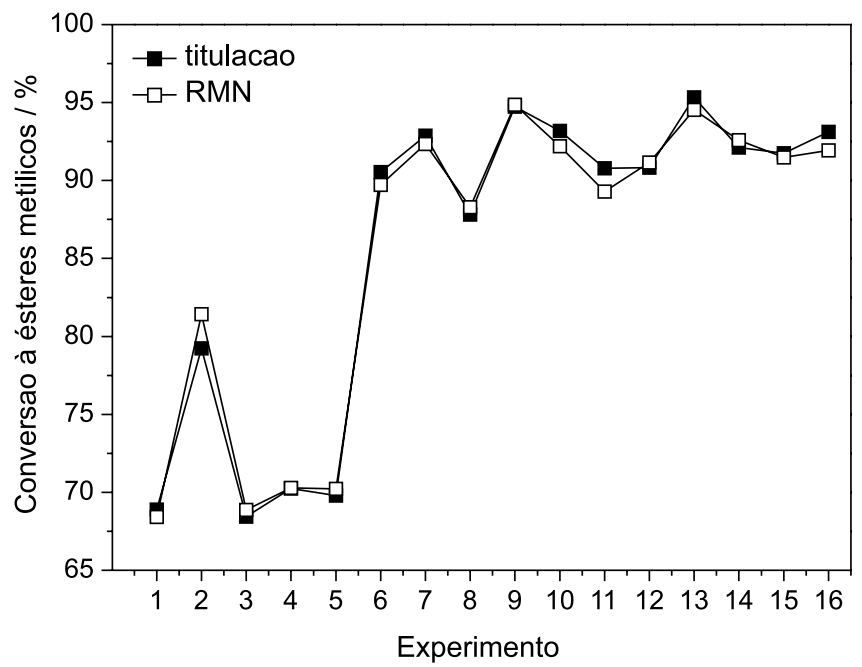

Figura 5. Comparação entre os dados gerados por titulação e obtidos por $R M N d e^{l} H$ 
e $12 \%$ de catalisador, tal reação apresentou ganho de conversão em relação à reação 5 de 25,54 pontos percentuais. Verifica-se pelos resultados mostrados na Tabela 3 que a variável razão molar apresentou um efeito de $+0,33$ pontos percentuais, mostrando pouca significância no aumento desta variável nos resultados obtidos. Quando do emprego da temperatura de $140{ }^{\circ} \mathrm{C}$ e comparando-se as reações 6 com 8 e 10 com 12 não foi verificado efeito positivo significativo, enquanto que para as reações conduzidas à $160^{\circ} \mathrm{C}$, somente quando se comparam as reações 11 com 13 foi verificado um efeito positivo discreto.

A variável temperatura mostrou efeito positivo de $+2,85$ pontos percentuais, em que as reações conduzidas à $160^{\circ} \mathrm{C}$ apresentaram maiores conversões em relação às reações sob $140^{\circ} \mathrm{C}$; este resultado é verificado comparando-se as reações com as mesmas condições de razão molar e quantidade de catalisador, para as reações 10 e 11 tal comportamento não foi verificado.

Analisando as reações empregando o catalisador, a variável teor de catalisador mostrou um efeito de $+1,04$ pontos percentuais; o aumento mais significativo é verificado quando são comparadas as reações de branco com as reações catalisadas, porém as diferenças entre o emprego de 8 e $12 \%$ de catalisador não são significativas, este é o possível motivo pela baixa magnitude do valor de efeito obtido. A interação entre as variáveis temperatura e razão molar apresentou um efeito de $+2,86$ pontos percentuais, isso indica que maiores resultados são obtidos com o aumento destas duas variáveis em conjunto. As variáveis temperatura e teor de catalisador mostraram um efeito de interação de $-1,79$ pontos percentuais, indicando que o aumento simultâneo destas variáveis contribuiu negativamente para a conversão a éster. Para a comparação entre as variáveis razão molar e teor de catalisador, observou-se um efeito de interação de $+0,77$ pontos percentuais, o qual é mais significativo que o efeito entre a variável razão molar isoladamente e a interação entre as variáveis temperatura e teor de catalisador.

Foi realizado um estudo da atividade catalítica do catalisador NaMMT- $\mathrm{ZrSO}_{4}$ em função do tempo e os resultados obtidos por RMN são mostrados na Tabela $1 \mathrm{~S}$, material suplementar.

Este estudo foi conduzido nas mesmas condições da reação 13, já que esta reação apresentou a maior conversão no planejamento fatorial descrito anteriormente. Verifica-se que o máximo de laurato de metila para o estudo sem a presença de catalisador é obtido com tempo de reação de $240 \mathrm{~min}$, em que foram produzidos $87,08 \%$ de éster. Para o estudo com a presença de catalisador verifica-se que em toda a faixa de tempo analisada a conversão a laurato de metila foi superior em comparação aos resultados sem a presença do catalisador no meio reacional. O máximo de éster obtido foi de 95,75\%, com um tempo de reação de $270 \mathrm{~min}$, porém este valor está próximo do valor de $94,53 \%$, obtido com tempo de $120 \mathrm{~min}$, demonstrando que o final da conversão é atingido próximo a 2 h. Para a triplicata de reações realizadas nas condições de razão molar de 9:1 e 10\% de catalisador (ponto central do planejamento fatorial, reações 14-16 - Tabela 3) verifica-se que os valores estão próximos, mostrando uma boa reprodutibilidade, tanto do método de síntese, quanto nos procedimentos de quantificação das amostras.

O catalisador foi submetido a dois testes de reuso, em condições de reação de razão molar $12: 1$, temperatura de $160{ }^{\circ} \mathrm{C}$ e teor de catalisador de $12 \%$. Verifica-se que o catalisador apresentou maior conversão a laurato de metila no primeiro ciclo de reação, em que a conversão foi de $95,33 \%$, porém as conversões obtidas para o segundo e terceiro ciclo de uso apresentam uma leve queda, com valores de 93,63 e 93,37\%, respectivamente, sendo que estes ainda são superiores à reação sem a presença de catalisador, indicando que o material pode ser reutilizado.

A fim de verificar a integridade do catalisador em sucessivas reações de esterificação metílica do ácido láurico, após cada ciclo de reuso o mesmo foi caracterizado pelas técnicas XRD e FTIR. A Figura 5S, material suplementar, mostra os difratogramas de raios $\mathrm{X}$ do catalisador antes do uso $\left(\mathrm{Na}-\mathrm{MMT}-\mathrm{ZrSO}_{4}\right)$ e após cada ciclo de reuso. Não foram verificadas diferenças significativas nos difratogramas de raios $\mathrm{X}$ para o catalisador, mesmo após o terceiro ciclo de uso. Verifica-se apenas a diminuição de intensidade do pico em $9,65^{\circ}$, o qual representa uma diminuição da ordem de empilhamento das lamelas ao longo do eixo basal. Esse fato é esperado já que as reações são conduzidas em condições agressivas de agitação mecânica e temperatura. Apesar de que somente algumas amostras foram monitoradas, não foram observados efeitos de lixívia de metais às fases de ésteres obtidas.

\section{Aplicação do catalisador em reações de esterificação metílica, sob condições de refluxo}

Foram realizados experimentos de esterificação metílica do ácido láurico em um sistema aberto, na temperatura de ebulição do metanol $\left(63^{\circ} \mathrm{C}\right)$ e tempo de $2 \mathrm{~h}$. As condições experimentais são mostradas na Tabela 4. Quando as reações foram conduzidas sem a presença do catalisador (reações 17-19), não foram observadas conversões a laurato de metila, já para as reações em que o catalisador foi empregado foram observadas conversões em torno de $30 \%$, mostrando atividade catalítica nas condições testadas. A maior conversão foi observada quando se empregou uma razão molar 12:1 e teor de catalisador de $12 \%$, obtendo-se $36,86 \%$ de laurato de metila (reação 23 ).

\section{Aplicação do catalisador em reações de esterificação etílica do ácido láurico}

Foram também investigadas as reações de esterificação etílica utilizando o catalisador Na-MMT-ZrSO $\mathrm{H}_{4}$, em que foi realizado um planejamento fatorial $2^{3}$. Os resultados são mostrados na Tabela 5.

Tabela 4. Conversão a laurato de metila em sistema aberto e temperatura de ebulição do metanol

\begin{tabular}{cccccc}
\hline \multirow{2}{*}{ Ensaio } & \multicolumn{2}{c}{ Condições experimentais } & \multicolumn{2}{c}{ Resultados (titulação) } & Resultados (RMN) \\
\cline { 2 - 6 } & RM & CAT & Acidez $(\%) * *$ & Conversão $(\%)$ & Éster $(\%) * *$ \\
\hline 17 & $6: 1$ & $*$ & $100,00 \pm 1,47$ & 0 & $4,40 \pm 0,26$ \\
18 & $12: 1$ & $*$ & $100,00 \pm 2,03$ & 0 & $1,59 \pm 0,19$ \\
19 & $9: 1$ & $*$ & $100,00 \pm 1,53$ & 30,06 & $3,01 \pm 0,28$ \\
20 & $6: 1$ & 8 & $69,94 \pm 0,64$ & 32,07 & $30,26 \pm 0,30$ \\
21 & $12: 1$ & 12 & $67,93 \pm 0,74$ & 29,46 & $32,02 \pm 1,66$ \\
22 & $6: 1$ & 12 & $70,54 \pm 0,12$ & 36,86 & $30,07 \pm 1,34$ \\
23 & $12: 1$ & 10 & $63,14 \pm 1,01$ & $35,27 \pm 0,20$ \\
24 & $9: 1$ & $67,14 \pm 1,50$ & 32,86 & $31,71 \pm 1,47$ \\
\hline
\end{tabular}

RM = razão molar álcool:ácido láurico; CAT = teor de catalisador em massa em relação ao ácido láurico; * = ausência de catalisador; ** = medidas realizadas em triplicata. 
Tabela 5. Planejamento fatorial $2^{3}$ para reações de esterificação etílica do ácido láurico utilizando o catalisador Na-MMT-ZrSO

\begin{tabular}{|c|c|c|c|c|c|c|c|}
\hline \multirow{2}{*}{ Ensaio } & \multicolumn{3}{|c|}{ Condições experimentais } & \multicolumn{2}{|c|}{ Resultados (titulação)** } & \multirow{2}{*}{$\begin{array}{l}\text { Ganho de conversão } \\
\text { Pontos percentuais }\end{array}$} & \multirow{2}{*}{$\begin{array}{c}\text { Resultados }(\mathrm{NMR})^{* * *} \\
\text { Éster }(\%)\end{array}$} \\
\hline & $\mathrm{T}\left({ }^{\circ} \mathrm{C}\right)$ & $\mathrm{RM}$ & CAT & Acidez $(\%)$ & Conversão (\%) & & \\
\hline 25 & 140 & $6: 1$ & $*$ & $50,15 \pm 1,19$ & 49,85 & - & $50,56 \pm 0,42$ \\
\hline 26 & 160 & $6: 1$ & $*$ & $28,30 \pm 0,47$ & 71,70 & - & $67,71 \pm 0,50$ \\
\hline 27 & 150 & $9: 1$ & $*$ & $47,88 \pm 0,92$ & 52,12 & - & $53,97 \pm 0,13$ \\
\hline 28 & 140 & $12: 1$ & $*$ & $65,88 \pm 0,94$ & 34,12 & - & $33,42 \pm 0,25$ \\
\hline 29 & 160 & $12: 1$ & $*$ & $53,36 \pm 1,37$ & 43,64 & - & $42,76 \pm 0,27$ \\
\hline 30 & $140(-)$ & $6: 1(-)$ & $8(-)$ & $39,34 \pm 1,19$ & 60,66 & 10,81 & $60,98 \pm 0,87$ \\
\hline 31 & $160(+)$ & $6: 1(-)$ & $8(-)$ & $18,22 \pm 0,41$ & 81,78 & 10,08 & $77,70 \pm 0,34$ \\
\hline 32 & $140(-)$ & $12: 1(+)$ & $8(-)$ & $49,15 \pm 1,05$ & 50,85 & 16,73 & $49,76 \pm 0,33$ \\
\hline 33 & $160(+)$ & $12: 1(+)$ & $8(-)$ & $17,85 \pm 1,36$ & 82,15 & 38,51 & $81,18 \pm 0,03$ \\
\hline 34 & $140(-)$ & 6:1 (-) & $12(+)$ & $31,41 \pm 0,47$ & 68,59 & 18,74 & $67,44 \pm 0,28$ \\
\hline 35 & $160(+)$ & 6:1 (-) & $12(+)$ & $16,65 \pm 0,74$ & 83,35 & 11,65 & $84,42 \pm 0,37$ \\
\hline 36 & $140(-)$ & $12: 1(+)$ & $12(+)$ & $42,88 \pm 1,38$ & 57,12 & 23,00 & $58,59 \pm 0,24$ \\
\hline 37 & $160(+)$ & $12: 1(+)$ & $12(+)$ & $22,48 \pm 1,00$ & 77,52 & 33,88 & $77,85 \pm 0,04$ \\
\hline 38 & $150(0)$ & 9:1 (0) & $10(0)$ & $31,25 \pm 0,58$ & 68,75 & 16,63 & $68,76 \pm 0,78$ \\
\hline 39 & $150(0)$ & 9:1 (0) & $10(0)$ & $32,38 \pm 1,00$ & 67,62 & 15,50 & $67,72 \pm 0,40$ \\
\hline 40 & $150(0)$ & 9:1 (0) & $10(0)$ & $31,28 \pm 1,18$ & 68,72 & 16,60 & $68,11 \pm 0,14$ \\
\hline
\end{tabular}

$\mathrm{T}$ = temperatura; $\mathrm{RM}$ = razão molar álcool:ácido láurico: $\mathrm{CAT}=$ teor de catalisador em massa em relação ao ácido láurico; os símbolos,+- e 0 representam o maior, menor e ponto central do planejamento fatorial; $*$ = ausência de catalisador; $* *$ medidas realizadas em triplicata.

Similarmente ao método descrito anteriormente para a determinação da conversão a ésteres metílicos por RMN, a determinação da eficiência das esterificações etílicas foi realizada com base na existência de sinais característicos nos espectros de RMN de ${ }^{1} \mathrm{H}$, que representam o ácido graxo e o éster etílico correspondente. Neste caso, a determinação baseou-se nas áreas dos sinais em 2,29 e 2,33 ppm, referentes aos grupos $\mathrm{CH}_{2}$ alfa carbonila presentes tanto no ácido graxo quanto no éster correspondente, e 4,12 ppm, referente ao grupo $\mathrm{CH}_{2}$ da etoxila presente somente no éster etílico (Figura 6).

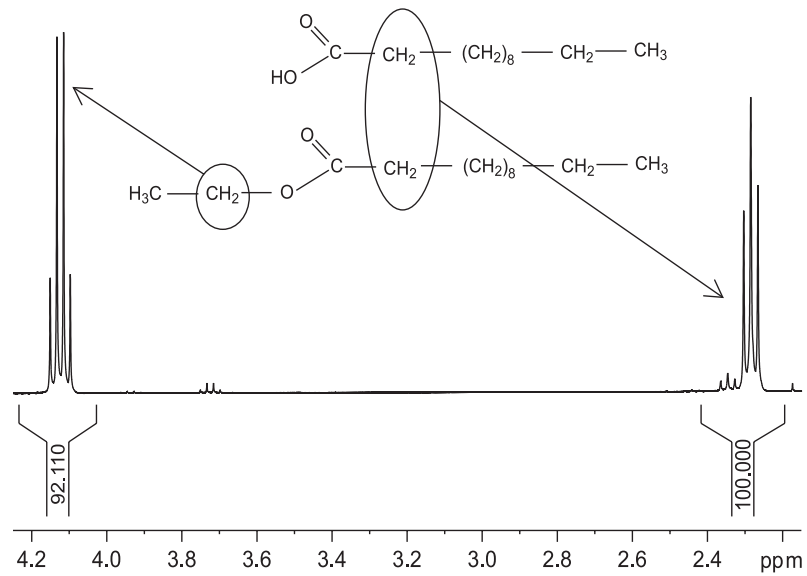

Figura 6. Determinação da percentagem de conversão a laurato de etila através de $\mathrm{RMN}$ de ${ }^{1} \mathrm{H}$

Uma vez que a relação intramolecular de hidrogênios $\left(-\mathrm{CH}_{2}\right.$ versus $-\mathrm{OCH}_{2}$ ) é de 2:2, ao referenciar a área dos sinais em 2,29 e 2,33 ppm para 100, o valor encontrado para a área do sinal em 4,12 ppm irá refletir diretamente a percentagem de éster convertido. Novamente, o método baseado em RMN de ${ }^{1} \mathrm{H}$ apresentou boa correlação ao método de titulação (Tabela 5).

A maior conversão a laurato de etila foi obtida na reação 35 , em que a conversão a éster atingiu $83,35 \%$, sendo que a reação foi conduzida sob temperatura de $160^{\circ} \mathrm{C}$, razão molar 6:1 e teor de catalisador de $12 \%$. O ganho de conversão comparando-se esta reação 26 foi de 11,65 pontos percentuais, porém o maior ganho de conversão foi observado comparando-se as reações 33 com 29, na qual obteve-se um ganho de 38,51 pontos percentuais.

O efeito apresentado pela variável razão molar foi de $-6,69$ pontos percentuais, em que se verifica um efeito negativo no aumento desta variável, pois aumentando-se a razão molar de 6:1 para 12:1 as conversões são menores; de maneira geral, tal comportamento é verificado comparando-se as reações conduzidas sob mesma temperatura e mesma quantidade de catalisador, exceto para a reação 31 quando comparada com a 33, na qual esse comportamento não foi observado.

A variável temperatura nas conversões mostradas na Tabela 3 mostrou um efeito de $+21,90$ pontos percentuais sendo, portanto, um efeito bastante significativo. Em todas as reações conduzidas a temperaturas mais elevadas, foram observadas maiores conversões a ésteres, quando as demais condições foram mantidas constantes.

Para a variável teor de catalisador foi observado um efeito de $+2,79$, mostrando que com o aumento do teor de catalisador, maiores conversões são obtidas; tal comportamento não foi observado entre as reações conduzidas a $160{ }^{\circ} \mathrm{C}$ e razão molar 12:1 (reações 33 e 37).

A interação verificada entre as variáveis temperatura e razão molar mostrou um efeito de $+3,96$ pontos percentuais, mostrando que o aumento simultâneo dessas duas variáveis tende a conduzir a maiores conversões; tal fato é verificado comparando-se a reação 30 $(60,66 \%)$ com a reação 33 (82,15\%). O efeito de interação verificado para o teor de catalisador juntamente com a variável temperatura foi de $-4,32$ pontos percentuais, demonstrando que o aumento simultâneo dessas variáveis possui efeito negativo na conversão a éster. A interação entre as variáveis razão molar e teor de catalisador é de -1,97 pontos percentuais; o efeito negativo apresentado pelo aumento destas duas variáveis é observado comparando a reação $30(60,66 \%)$ com a reação $36(57,12 \%)$ e a reação $31(81,78 \%)$ com a reação $37(77,52 \%)$.

As conversões obtidas nos experimentos do ponto central (reações 
38-40) apresentam valores muito próximos, indicando boa reprodutibilidade do método de síntese do laurato de etila sob diferentes condições de reação.

O maior ganho de conversão foi observado para a reação $33 \mathrm{em}$ comparação à reação 29 , na qual se verificou um aumento de 33,88 pontos percentuais, em condições de reação de razão molar 12:1, $8 \%$ de catalisador e temperatura de $160^{\circ} \mathrm{C}$.

Foi realizado um teste em condições de razão molar 6:1, $12 \%$ de catalisador, temperatura de $160{ }^{\circ} \mathrm{C}$ e tempo de $5 \mathrm{~h}$, no qual se obteve uma conversão a laurato de etila de $91,73 \%$, com um ganho de conversão 15,80 pontos percentuais em relação à conversão térmica. Este resultado implica que a variável tempo contribui positivamente na conversão a laurato de etila.

O material foi testado na esterificação metílica dos ácidos graxos que compõem o tall oil, onde se obteve uma diminuição na acidez de 84,75\%, em condição de razão molar de 12:1 (metanol:tall oil), 160 ${ }^{\circ} \mathrm{C}$ e $12 \%$ de catalisador. Este resultado correspondeu a um ganho de conversão de 14,86 p.p. em relação à conversão térmica conduzida nas mesmas condições experimentais, porém sem a presença do catalisador, indicando que o material apresenta atividade catalítica em matrizes graxas complexas.

\section{CONCLUSÕES}

Com base nos resultados obtidos demonstrou-se que o argilomineral montmorilonita, após modificação com óxido de zircônio e sulfato de amônio, pode ser empregado como catalisador heterogêneo em reações de esterificação metílica e etílica de ácidos graxos, na produção de biodiesel. O catalisador apresentou alta eficiência nas conversões a ésteres metílicos e etílicos mesmo após sucessivas reutilizações, apresentado as vantagens da alta disponibilidade e baixo custo do argilomineral, além da facilidade de preparação e recuperação do catalisador do meio reacional.

\section{MATERIAL SUPLEMENTAR}

Está disponível em http://quimicanova.sbq.org.br, em arquivo PDF, com acesso livre. A Figura $1 \mathrm{~S}$ mostra os espectros de FTIR das amostras Na-MMT e Na-MMT-ZrSO $\mathrm{N}_{4}$; a Figura 2S, as micrografias das amostras MMT, Na-MMT e Na-MMT-ZrSO $\mathrm{H}_{4}$, obtidas por microscopia eletrônica de varredura; a Figura $3 \mathrm{~S}$ mostra as curvas de TGA/DTA do catalisador Na-MMT-ZrSO ${ }_{4}$; a Figura 4S, o espectro de FTIR do material Na-MMT-ZrSO $\mathrm{S}_{4}$ após tratamento com piridina; a Figura 5S, os difratogramas de raios $\mathrm{X}$ do catalisador Na-MMT$\mathrm{ZrSO}_{4}$ (a) e após primeiro (b), segundo (c) e terceiro ciclo de uso (d). A Tabela $1 \mathrm{~S}$ mostra os resultados das reações de esterificação metílica do ácido láurico, quando da utilização de uma razão molar $12: 1$, teor de catalisador de $12 \%$ e temperatura de $160{ }^{\circ} \mathrm{C}$.

\section{AGRADECIMENTOS}

Às agências de fomento CAPES, FINEP, CNPq e Fundação Araucária, por financiar o presente projeto e ao Centro de Microscopia Eletrônica (CME) e Laboratório de Análise de Minerais e Rochas (LAMIR), ambos da UFPR, pelas análises de MEV/EDS e TGA/ DTA, respectivamente.

\section{REFERÊNCIAS}

1. Anand, K.; Sharma, R. P.; Mehta, P. S.; Appl. Therm. Eng. 2011, 31, 235.

2. Atadashi, I. M.; Aroua, M. K.; Aziz, A. A.; Renew. Energ. 2011, 36, 437.

3. Keera, S. T.; El Sabagh, S. M.;Taman, A. R.; Fuel 2011, 90, 42.

4. Carriazo, J.; Guelou, E.; Barrault, J.; Tatibouet, J. M.; Molina, R.; Moreno, S.; Catal. Today 2005, 107-108, 126.

5. Chen, Y. H.; Chen, J. H.; Chang, C. Y.; Chang, C. C.; Bioresour Technol. 2010, 101, 9521.

6. Pisarello, M. L.; Dalla Costa, B.; Mendow, G.; Querini, C. A.; Fuel Process. Technol. 2010, 91, 1005.

7. Wen, Z.; Yu, X.; Tu, S. T.; Yan, J.; Dahlquist, E.; Bioresour. Technol. 2010, 101, 9570.

8. Ramesh, S.; Prakash, B. S. J.; Bhat, Y. S.; Appl. Clay Sci. 2010, 48, 159.

9. Tesser, R.; Casale, L.; Verde, D.; Di Serio, M.; Santacesaria, E.; Chem. Eng. J. 2010, 157, 539.

10. Bouguerra Neji, S.; Trabelsi, M.; Frikha, M.; Energies 2009, 2, 1107.

11. Ropero-Vega, J. L.; Aldana-Pérez, A.; Gómez, R.; Niño-Gómez, M. E.; Appl. Catal., A 2010, 379, 24.

12. Mello, V. M.; Pousa, G. P. A. G.; Pereira, M. S. C.; Dias, I. M.; Suarez, P. A. Z.; Fuel Process. Technol. 2011, 92, 53.

13. Zieba, A.; Drelinkiewicz, A.; Konyushenko, E. N.; Stejskal, J.; Appl. Catal., A 2010, 383, 169.

14. Kafuku, G.; Lam, M. K.; Kansedo, J.; Lee, K. T.; Mbarawa, M.; Fuel Process. Technol. 2010, 91, 1525.

15. Zatta, L.; Gardolinski, J. E. F. d. C.; Wypych, F.; Appl. Clay Sci. 2011, $51,165$.

16. Reddy, C.; Iyengar, P.; Nagendrappa, G.; Prakash, B.; Catal. Lett. 2005, $101,87$.

17. Vijayakumar, B.; Nagendrappa, G.; Jai Prakash, B.; Catal. Lett. 2009, $128,183$.

18. Gil, A.; Korili, S.A.; Trujillano, R.; Vicente, M. A.; Appl. Clay Sci. 2011, $53,97$.

19. Kloprogge, J. T.; Duong, L. V.; Frost, R. L.; Environ. Geol. 2005, 47, 967.

20. Luna, F. J.; Schuchardt, U.; Quim. Nova 1999, 22, 104.

21. Chipera, S. J.; Bish, D. L.; Clays Clay Miner. 2001, 49, 398.

22. Borden, D.; Giese, R. F.; Clays Clay Miner. 2001, 49, 444.

23. AOCS; Official Methods and Recommended Practices of the American Oil Chemist's Society, 5 ${ }^{\text {th }}$ ed., Champaign: Illinois 1998.

24. Cordeiro, C. S.; Tese de Doutorado, Universidade Federal do Paraná, Brasil, 2009.

25. do Nascimento, L. A. S.; Angélica, R. S.; da Costa, C. E. F.; Zamian, J. R.; da Rocha Filho, G. N.; Appl. Clay Sci. 2011, 51, 267.

26. Viani, A.; Gualtieri, A. F.; Artioli, G.; Am. Mineral. 2002, 87, 966.

27. Madejova, J.; Komadel, P.; Clays Clay Miner. 2001, 49, 410.

28. Tyagi, B.; Chudasama, C. D.; Jasra, R. V.; Spectrochim. Acta, Part A 2006, 64, 273.

29. Xu, J. M.; Jiang, J. C.; Sun, Y. J.; Lu, Y. J.; J. Fuel Chem. Technol. 2008, $36,421$.

30. Sing, K. S. W.; Everett, D. H.; Haul, R. A. W.; Moscou, L.; Pierotti, R. A.; Rouquerol, J.; Siemieniewsk, T.; Pure Appl. Chem. 1985, 57, 603.

31. Reddy, C. R.; Bhat, Y. S.; Nagendrappa, G.; Jai Prakash, B. S.; Catal. Today 2009, 141, 157.

32. da Silva, C. W.; Campos, F. R.; Simonelli, F.; Lenz, C. A.; Ferreira, A. G.; Barison, A.; Magn. Reson. Chem. 2010, 48, 642.

33. Monteiro, M. R.; Ambrozin, A. R. P.; Santos, M. S.; Boffo, E. F.; Pereira-Filho, E. R.; Lião, L. M.; Monteiro, A. G. F.; Talanta 2009, 78, 660. 


\section{MONTMORILONITA MODIFICADA COMO CATALISADOR HETEROGÊNEO EM REAÇÕES DE} ESTERIFICAÇÃO (M)ETÍLICA DE ÁCIDO LÁURICO

Leandro Zatta, Angelita Nepel, Andersson Barison e Fernando Wypych*

Departamento de Química, Universidade Federal do Paraná, CP 19081, 81531-980 Curitiba - PR, Brasil

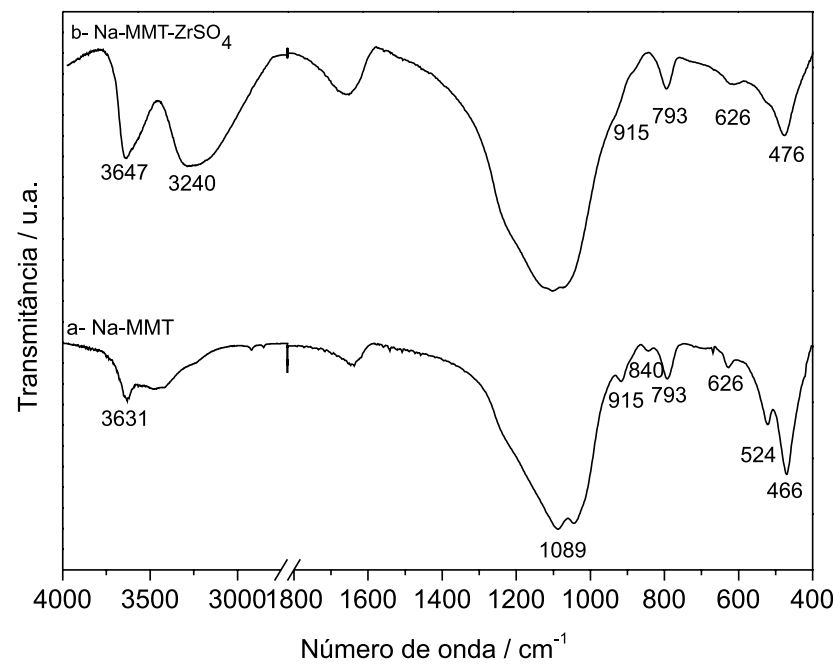

Figura 1S. Espectros de FTIR das amostras Na-MMT (a) e Na-MMT-ZrSO ${ }_{4}(b)$
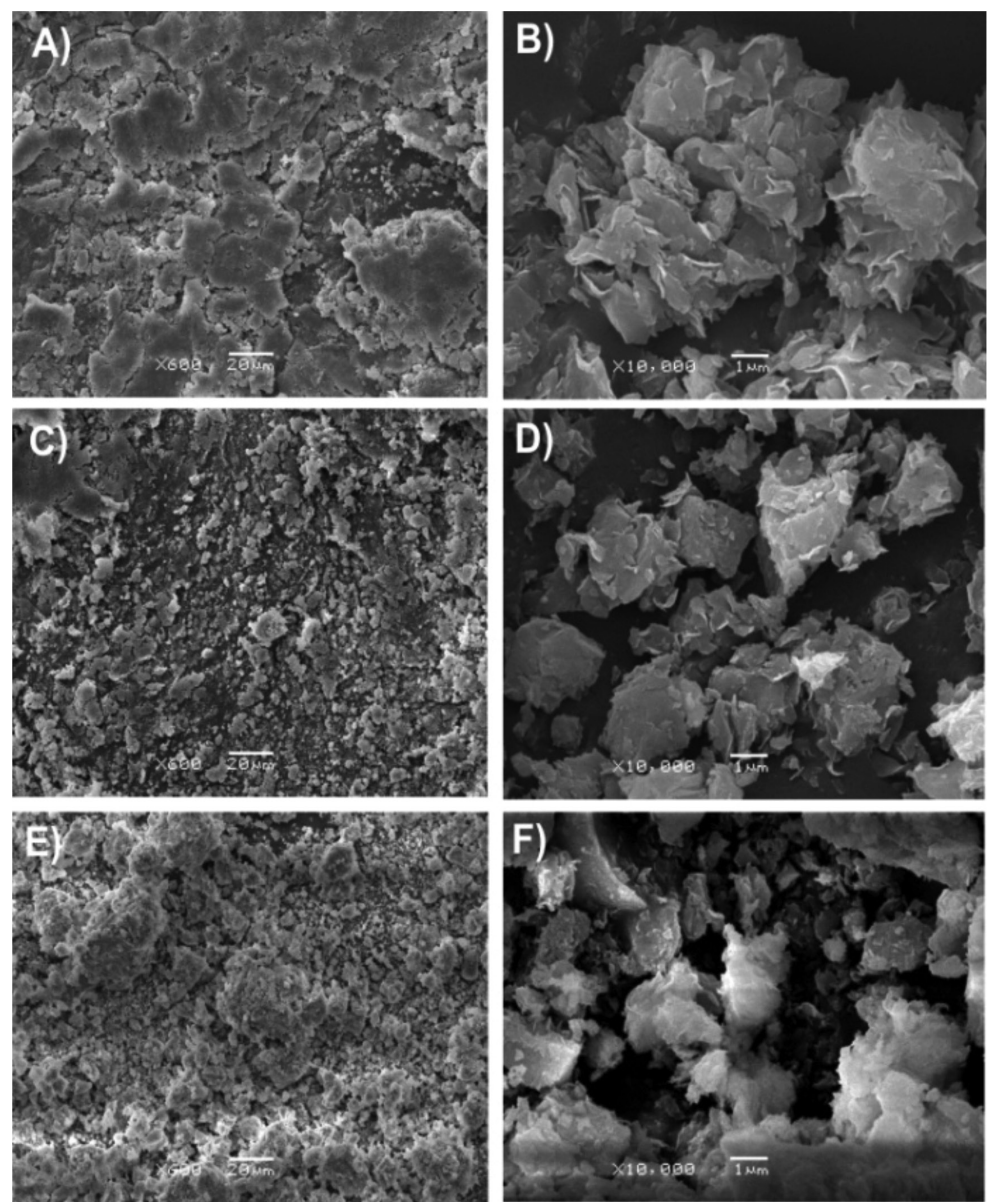

Figura 2S. Imagens de microscopia eletrônica de varredura das amostras: $M M T(A, B), N a-M M T(C, D)$ e Na-MMT-ZrSO ${ }_{4}(E, F)$

*e-mail: wypych@ufpr.br 


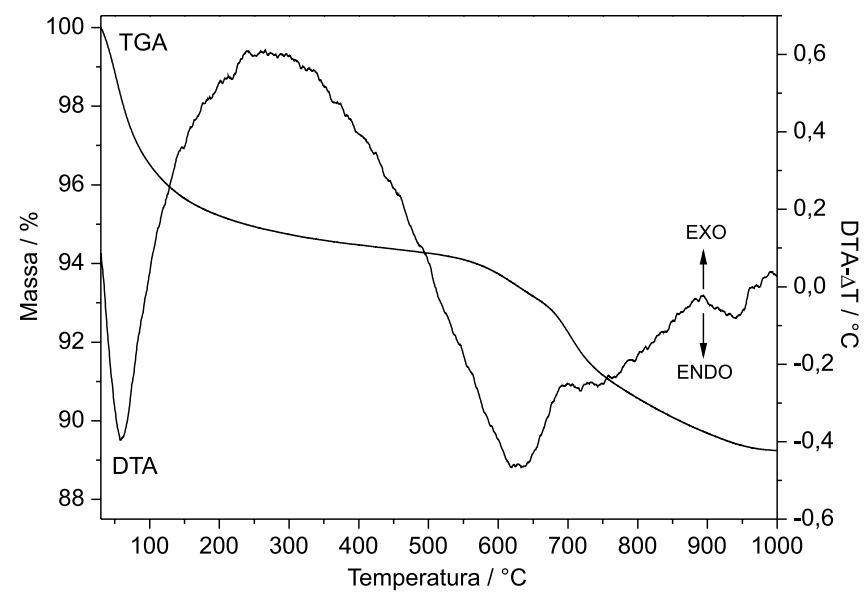

Figura 3S. Curvas de análise térmica (TGA e DTA) da amostra Na-MMT-ZrSO ${ }_{4}$

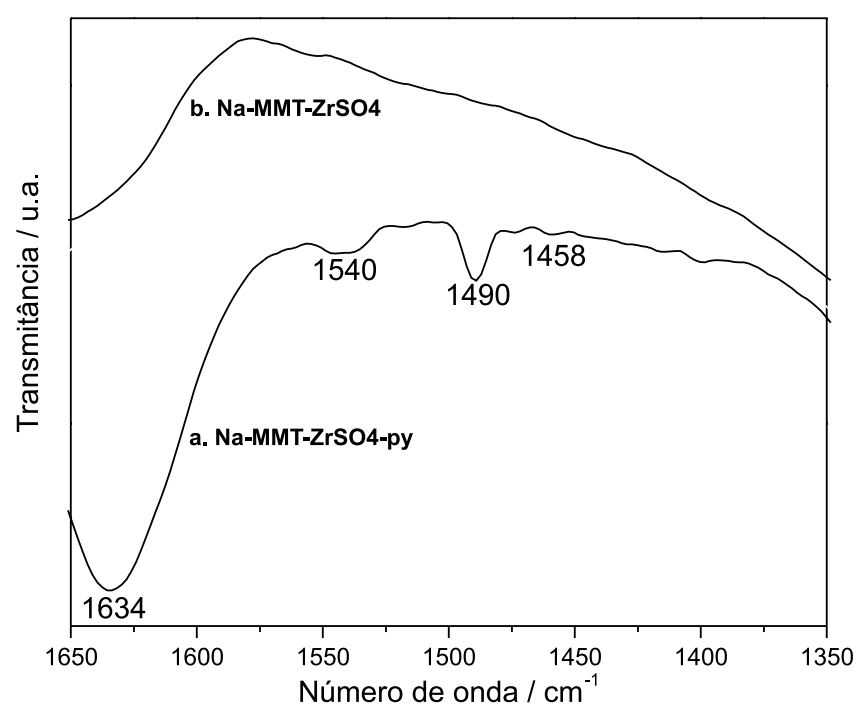

Figura 4S. Espectro de FTIR da amostra Na-MMT-ZrSO ${ }_{4}$ tratada com piridina (a) e sem tratamento com piridina (b)

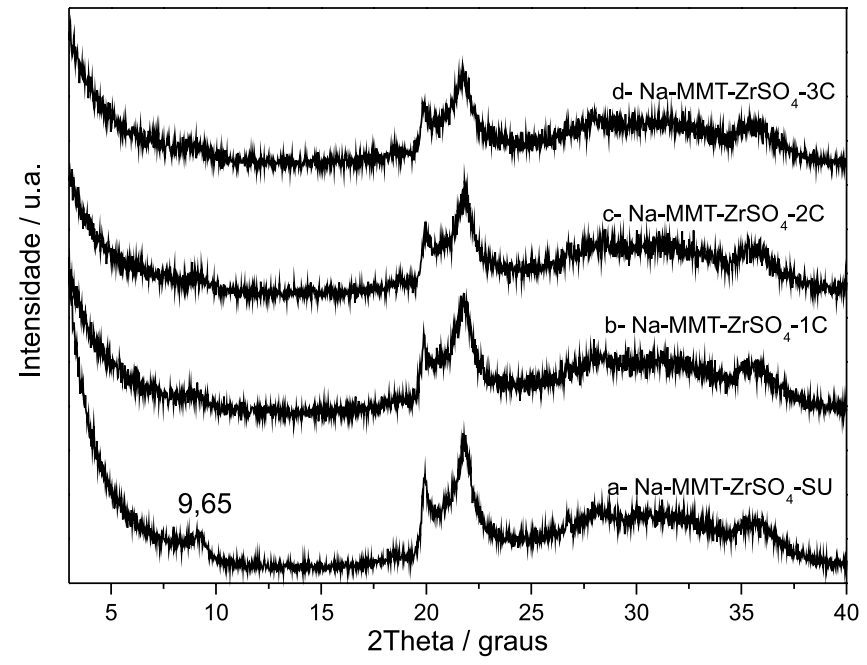

Figura 5S. Difratogramas de Raios $\mathrm{X}$ do catalisador Na-MMT-ZrSO $\mathrm{N}_{4}($ a) $e$ após primeiro (b), segundo (c) e terceiro ciclo de uso (d). Reações de esterificação metílica do ácido láurico (razão molar 12:1, teor de catalisador de $12 \%$ e temperatura de $160^{\circ} \mathrm{C}$ )

Tabela 1S. Conversão a laurato de metila em função do tempo de reação

\begin{tabular}{|c|c|c|c|c|c|}
\hline \multirow{3}{*}{ Tempo (min.) } & \multicolumn{5}{|c|}{ Resultados RMN de ${ }^{1} \mathrm{H}$} \\
\hline & \multicolumn{2}{|c|}{ Conversão térmica * } & \multicolumn{2}{|c|}{ Conversão catalisada * } & \multirow{2}{*}{$\begin{array}{c}\text { Ganho de } \\
\text { conversão (\%) }\end{array}$} \\
\hline & Acidez (\%) & Conversão (\%) & Acidez $(\%)$ & Conversão (\%) & \\
\hline 30 & $49,99 \pm 0,83$ & 50,01 & $27,30 \pm 0,90$ & 72,70 & 22,69 \\
\hline 60 & $35,90 \pm 1,31$ & 64,10 & $18,46 \pm 0,48$ & 81,54 & 17,44 \\
\hline 90 & $30,3 \pm 0,14$ & 69,70 & $12,39 \pm 0,14$ & 87,61 & 17,91 \\
\hline 120 & $24,67 \pm 0,25$ & 75,33 & $5,47 \pm 1,29$ & 94,53 & 19,20 \\
\hline 150 & $18,27 \pm 0,03$ & 81,73 & $5,48 \pm 0,79$ & 94,52 & 12,79 \\
\hline 180 & $16,69 \pm 0,36$ & 83,31 & $5,76 \pm 0,41$ & 94,24 & 10,93 \\
\hline 210 & $14,36 \pm 0,14$ & 85,64 & $3,49 \pm 0,21$ & 96,51 & 10,87 \\
\hline 240 & $12,92 \pm 0,33$ & 87,08 & $4,36 \pm 0,20$ & 95,64 & 8,56 \\
\hline 270 & $12,82 \pm 0,04$ & 87,18 & $4,25 \pm 0,23$ & 95,75 & 8,57 \\
\hline
\end{tabular}

\footnotetext{
* = medidas realizadas em triplicata.
} 